\title{
Reassessment of the Taxonomic Position of Rickettsiella grylli
}

\author{
V. ROUX, ${ }^{1}$ M. BERGOIN, ${ }^{2}$ N. LAMAZE, ${ }^{1}$ AND D. RAOULT ${ }^{1 *}$ \\ Unité des Rickettsies, CNRS UPRESA 6020, Faculté de Médecine, 13385 Marseille, ${ }^{1}$ and Laboratoire de Pathologie \\ Comparée, INRA-UA 2209 du CNRS, Université des Sciences et Techniques du Languedoc, \\ 34060 Montpellier cedex, ${ }^{2}$ France
}

\begin{abstract}
We determined the 16S rRNA gene sequence of Rickettsiella grylli, an intracellular parasite of Gryllus bimaculatus and related species of crickets. Phylogenetic inferences made from alignment of this sequence with the sequences of other bacteria demonstrated that $R$. grylli is most closely related to Coxiella burnetii and Legionella species in the $\gamma$ subclass of the phylum Proteobacteria. $R$. grylli was previously thought to be related to members of the order Rickettsiales, but the representatives of this order have been shown to be members of the $\alpha 1$ subclass of the Proteobacteria. Our results indicate that $R$. grylli should be removed from the order Rickettsiales.
\end{abstract}

Members of the genus Rickettsiella are intracellular procaryotic pathogens of invertebrates, including insects, crustaceans, and arachnids. Bacterial replication takes place in cell vacuoles in the fat body, the hepatopancreas, and other organs. Rickettsiella species were classified in the order Rickettsiales, the family Rickettsiaceae, and the tribe Wolbachieae; however, this position was determined solely on the basis of the close association of these organisms with arthropods and their intravacuolar location. Three Rickettsiella species are currently recognized (25). The type species Rickettsiella popilliae, was first described in 1951 as Coxiella popilliae and is the bacterium responsible for blue disease, a fatal infection of the larvae of the Japanese beetle, Popillia japonica (6). Rickettsiella grylli and Rickettsiella chironomii were described subsequently by Vago and Martoja and by Weiser, respectively $(19,24)$. As Rickettsiella spp. replicate by using a cycle that mimics that of Chlamydia species, some investigators have suggested that these organisms more closely resemble members of the genus Chlamydia than members of the genus Rickettsia and should be transferred to the order Chlamydiales. In order to clarify the taxonomic status and the phylogenetic position of Rickettsiella grylli, we sequenced its 16S rRNA-encoding gene.

The Rickettsiella grylli strain was provided by Max Bergoin. The organisms included in the phylogenetic analysis were Ehrlichia risticii (HRC-IL ${ }^{\mathrm{T}}$ (= ATCC VR-986 ${ }^{\mathrm{T}}$ ) (21), Ehrlichia chaffeensis Arkansas (1), Ehrlichia phagocytophila Old Sourhope (1), Wolbachia pipientis (12), Rickettsia conorii Moroccan $^{\mathrm{T}}$ (= ATCC VR-141 $\left.{ }^{\mathrm{T}}\right)$ (16), Rickettsia prowazekii Brienl $^{\mathrm{T}}$ (= ATCC VR-142 ${ }^{\mathrm{T}}$ ) (21), Orientia tsutsugamushi Gilliam $^{\mathrm{T}}$ (= ATCC VR-312 ${ }^{\mathrm{T}}$ ) (16), Bartonella quintana Fuller ${ }^{\mathrm{T}}$ (= ATCC VR-358 ${ }^{\mathrm{T}}$ ) (13), Bartonella bacilliformis ATCC $35685^{\mathrm{T}}$ (11), Brucella abortus 11-19 (5), Coxiella burnetii Q117 (21), Legionella israelensis Bercovier-4 ${ }^{\mathrm{T}}\left(=\right.$ ATCC $\left.43119^{\mathrm{T}}\right)(9)$, Legionella anisa ATCC $35292^{\mathrm{T}}$ (15), Legionella pneumophila ATCC 33215 ${ }^{\mathrm{T}}$ (15), Acinetobacter Iwoffi ATCC 17925 (2), Pseudomonas aeruginosa DSM50071 (18), Escherichia coli (7), Francisella tularensis Utah 112 (= ATCC 15482) (26), Wolbachia persica ATCC VR-331 ${ }^{\mathrm{T}}$ (21), Mycoplasma pneumoniae $\mathrm{FH}$ (= ATCC 15531) (23), and Chlamydia psittaci $6 \mathrm{BC}^{\mathrm{T}}$ (22).

DNA was extracted from purified elementary bodies by us-

* Corresponding author. Mailing address: Unité des Rickettsies, CNRS UPRESA 6020, Faculté de Médecine, 27 Bd. Jean Moulin, 13385 Marseille, France. Phone: (33) 4-91-83-43-75. Fax: (33) 4-91-8303-90. E-mail: didier.raoult@medecine.univ-mars.fr. ing Qiagen columns (QIAamp tissue kit; QIAGEN, Hilden, Germany). Amplification of the 16S rRNA gene from this extract was performed by using a PCR incorporating primers fD1 and rp2, as previously described (20). The PCR products were purified by using Qiagen columns (QIAquick Spin PCR purification kit), and sequencing reactions were carried out by using an AmpliCycle sequencing kit (Perkin-Elmer Corp., Foster City, Calif.) according to the manufacturer's instructions. The products of sequencing reactions were resolved and translated into sequence data by using an A.L.F. DNA sequencer (Pharmacia LKB) and associated software. The sequence of Rickettsiella grylli was aligned with other bacterial 16S rRNA gene sequences by using the multisequence alignment program CLUSTAL. Phylogenetic relationships were inferred by using the PHYLIP software package (8). An evolutionary distance matrix, generated by DNADIST, was determined by the method of Kimura (10). This matrix was used to infer a dendrogram by using the neighbor-joining method (17). The data were also examined by performing a parsimony analysis (DNAPARS). The stabilities of the predicted branching orders were assessed by generating a consensus tree from 100 trees derived from bootstrap samples of the original alignment by using SEQBOOT and CONSENSE in the same package.

The phylogenetic tree derived from the distance matrix analysis is presented in Fig. 1, and this tree demonstrates that Rickettsiella grylli belongs to the $\gamma$ subclass of the phylum Proteobacteria and shares a common line of descent with Coxiella burnetii and the genus Legionella. The branching order in the tree derived from the parsimony analysis was the same as the branching order in Fig. 1. The order Rickettsiales has recently undergone substantial taxonomic reassessment on the basis of $16 \mathrm{~S}$ ribosomal DNA (rDNA) sequence comparisons, which have revealed a high degree of evolutionary diversity. Although members of the genera Rickettsia, Orientia, Ehrlichia, Cowdria, Anaplasma, and Neorickettsia and the species W. pipientis group together in the $\alpha 1$ subclass of the class Proteobacteria, other species have been shown to fall elsewhere. Rochalimaea, Grahamella, and Bartonella spp., all of which are members of the genus now unified as Bartonella, form a distinct lineage within the $\alpha 2$ subclass of this phylum $(3,4)$, whereas Coxiella burnetii and $W$. persica are phylogenetically remote and belong to the $\gamma$ subclass (21). Very recently, Haemobartonella and Eperythrozoon species have been shown to share evolutionary descent with the gram-positive members of the family Mycoplasmaceae (14). Our results support this phylogenetic diversity and provide a basis for removal of Rickettsiella 


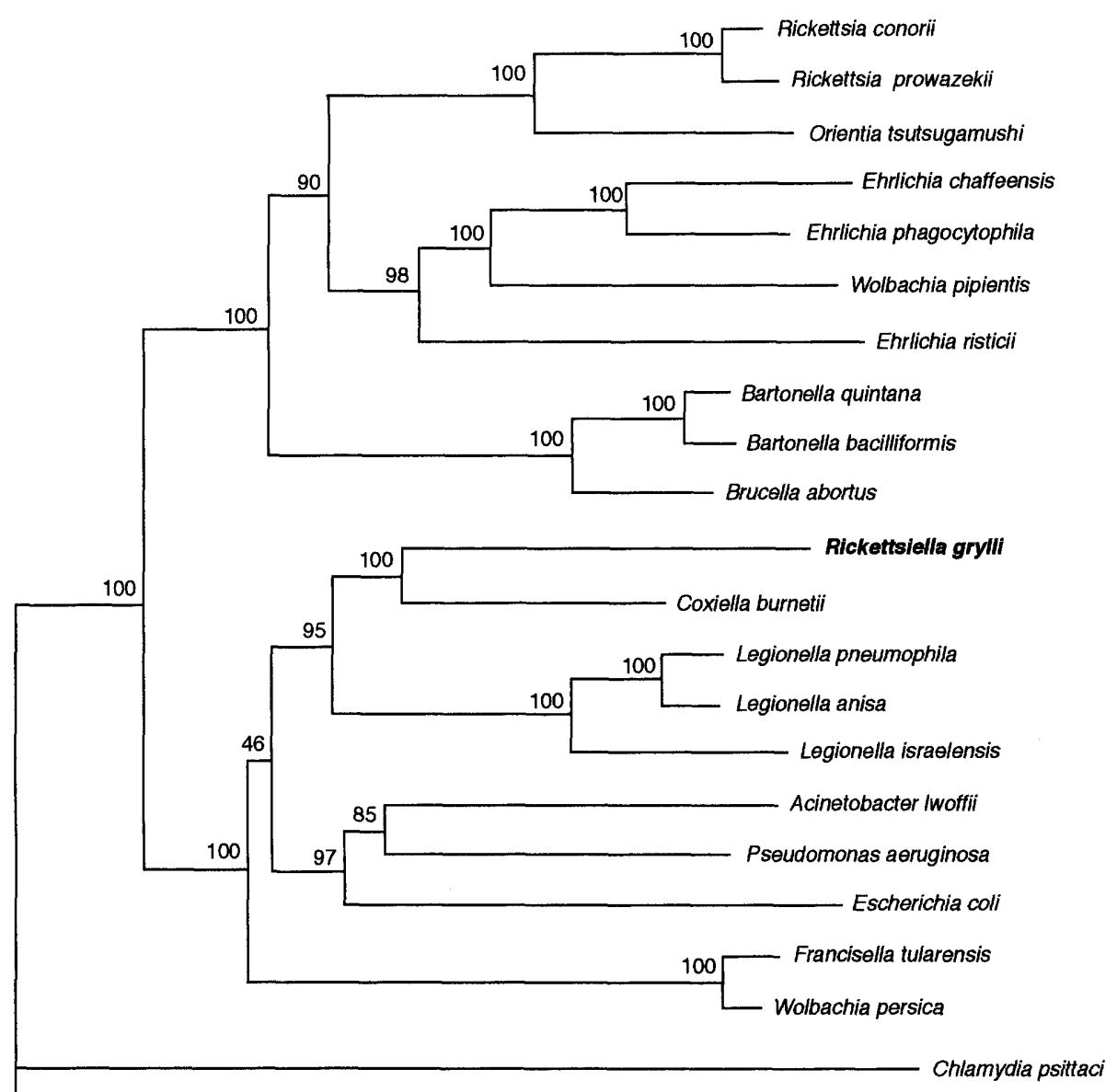

Mycoplasma pneumoniae

FIG. 1. Phylogenetic tree obtained from a neighbor-joining analysis of 16S rRNA sequences, showing the position of Rickettsiella grylli in the $y$ subclass of the class Proteobacteria. Scale bar $=10 \%$ difference. Bootstrap values from 100 analyses are shown at the branch points of the tree. The accession numbers of the sequences of the organisms used in the analysis are as follows: Ehrlichia risticii, M21290; Ehrlichia chaffeensis, M73222; Ehrlichia phagocytophila, M73220; Wolbachia pipientis, X61768; Rickettsia conorii, L36105; Rickettsia prowazekii, M21789; Orientia tsutsugamushi, L36222; Bartonella quintana, M73228; Bartonella bacilliformis, M65249; Brucella abortus, X13695; Rickettsiella grylli, U97547; Coxiella burnetii, M21291; Legionella israelensis, Z32640; Legionella anisa, X73394; Legionella pneumophila, X73402; Acinetobacter Iwoffii, U10875; Pseudomonas aeruginosa, X06684; Escherichia coli, M24996; Francisella tularensis, L26084; Wolbachia persica, M21292; Mycoplasma pneumoniae, M29061; and Chlamydia psittaci, M13769.

grylli from the order Rickettsiales. Determination of the $16 \mathrm{~S}$ rDNA sequences of Rickettsiella popilliae and Rickettsiella chironomi is required to determine if the genus Rickettsiella as a whole is misplaced in the Rickettsiales and if its members are phylogenetically homologous. It is interesting that the initial identification of Rickettsiella popilliae as Coxiella popilliae (6) is consistent with our findings. However, the similarity of the developmental cycles of Rickettsiella grylli and the genus Chlamydia does not seem to be ancestral but rather is the result of convergent evolution of several strictly intracellular bacteria.

Nucleotide sequence accession number. The nucleotide sequence of the 16S rDNA of Rickettsiella grylli has been deposited in the GenBank database under accession no. U97547.

\section{REFERENCES}

1. Anderson, B. E., J. E. Dawson, D. D. Jones, and K. H. Wilson. 1991. Ehrlichia chaffeensis, a new species associated with human ehrlichiosis. J. Clin. Microbiol. 29:2838-2842.
2. Ban, H. K., and K. L. Chua. Unpublished data.

3. Birtles, R. J., T. G. Harrison, N. A. Saunders, and D. H. Molyneux. 1995. Proposals to unify the genera Grahamella and Bartonella, with the descriptions of Bartonella talpae comb. nov., Bartonella peromysci comb. nov., and three new species, Bartonella grahamii sp. nov., Bartonella taylorii sp. nov., and Bartonella doshiae sp. nov. Int. J. Syst. Bacteriol. 45:1-8.

4. Brenner, D. J., S. P. O'Connor, H. H. Winkler, and A. G. Steigerwalt. 1993. Proposals to unify the genera Bartonella and Rochalimaea, with descriptions of Bartonella quintana comb. nov., Bartonella vinsonii comb. nov., Bartonella henselae comb. nov., and Bartonella elizabethae comb. nov., and to remove the family Bartonellaceae from the order Rickettsiales. Int. J. Syst. Bacteriol. 43:777-786.

5. Dorsch, M., E. Moreno, and E. Stackebrandt. 1989. Nucleotide sequence of the 16S rRNA from Brucella abortus. Nucleic Acids Res. 17:1765.

6. Dutky, S. R., and E. L. Gooden. 1951. Coxiella popilliae, n. sp., a rickettsia causing blue disease of Japanese beetle larvae. J. Bacteriol. 63:743-750.

7. Ehresmann, C., P. Stiegler, P. Fellner, and J. P. Ebel. 1975. The determination of the $16 \mathrm{~S}$ ribosomal RNA of Escherichia coli. III. Further studies. Biochimie 57:711-748.

8. Felsenstein, J. 1991. PHYLIP, version 3.4. University of Washington, Seattle.

9. Hookey, J. V., N. A. Saunders, N. Fry, R. J. Birtles, and T. G. Harrison. 1996. 
Phylogeny of Legionellaceae based on small-subunit ribosomal DNA sequences and proposal of Legionella lytica comb. nov. for Legionella-like amoebal pathogens. Int. J. Syst. Bacteriol. 46:526-531.

10. Kimura, M. 1980. A simple method for estimating evolutionary rate of base substitutions through comparative studies of nucleotide sequences. J. Mol. Evol. 16:111-120.

11. O'Connor, S. P., M. Dorsch, A. G. Steigerwalt, D. J. Brenner, and E. Stackebrandt. 1991. 16S rRNA sequences of Bartonella bacilliformis and cat scratch disease bacillus reveal phylogenetic relationships with the alpha-2 subgroup of the class Proteobacteria. J. Clin. Microbiol. 29:2144-2150.

12. O'Neil, S. L., R. Giordano, A. M. Colebert, T. L. Karr, and H. M. Robinson. 1992. 16S rRNA phylogenetic analysis of the bacterial endosymbionts associated with cytoplasmic incompatibility in insects. Proc. Natl. Acad. Sci. USA 89:2699-2702.

13. Regnery, R. L., B. E. Anderson, J. E. Clarridge III, M. C. RodriguezBarradas, D. C. Jones, and J. H. Carr. 1992. Characterization of a novel Rochalimaea species, $R$. henselae sp. nov., isolated from blood of a febrile, human immunodeficiency virus-positive patient. J. Clin. Microbiol. 30:265274.

14. Rikihisa, Y., M. Kawahara, B. Wen, G. Kociba, P. Fuerst, F. Kawamori, C. Suto, S. Shibata, and M. Futohashi. 1997. Western immunoblot analysis of Haemobartonella muris and comparison of 16S rRNA gene sequences of $H$. muris, H. felis, and Eperythrozoon suis. J. Clin. Microbiol. 35:823-829.

15. Ross, T., B. Heidrich, P. N. Robinso, F. J. Fehrenbach, and A. Rolfs. Unpublished data.

16. Roux, V., and D. Raoult. 1995. Phylogenetic analysis of the genus Rickettsia by 16 S rDNA sequencing. Res. Microbiol. 146:385-396.
17. Saitou, N., and M. Nei. 1987. The neighbor-joining method: a new method for reconstructing phylogenetic trees. Mol. Biol. Evol. 4:406-425.

18. Toschka, H. Y., P. Hoepfel, W. Ludwig, K. H. Schleifer, N. Ulbrich, and V. A Erdmann. 1988. Complete nucleotide sequence of a 16S ribosomal RNA gene from Pseudomonas aeruginosa. Nucleic Acids Res. 16:2348.

19. Vago, C., and R. Martoja. 1963. Une rickettsiose chez les Gryllidae (Orthoptera). C.R. Acad. Sci. 256:1045-1047.

20. Weisburg, W. G., S. M. Barns, D. A. Pelletier, and D. J. Lane. 1991. 16S ribosomal DNA amplification for phylogenetic study. J. Bacteriol. 173:697703.

21. Weisburg, W. G., M. E. Dobson, J. E. Samuel, G. A. Dasch, L. P. Mallavia, O. Baca, L. Mandelco, J. E. Sechrest, E. Weiss, and C. R. Woese. 1989 Phylogenetic diversity of the rickettsiae. J. Bacteriol. 171:4202-4206.

22. Weisburg, W. G., T. P. Hatch, and C. R. Woese. 1986. Eubacterial origin of chlamydiae. J. Bacteriol. 167:570-574.

23. Weisburg, W. G., J. G. Tully, D. L. Rose, J. P. Petzel, H. Oyaizu, D. Yang, L Mandelco, J. Sechrest, T. G. Lawrence, J. L. Van Etten, J. Maniloff, and C. R. Woese. 1989. A phylogenetic analysis of the mycoplasmas: basis for their classification. J. Bacteriol. 171:6455-6467.

24. Weiser, J. 1963. Diseases of insects of medical importance in Europe. Bull W. H. O. 28:121-127.

25. Weiss, E., and J. W. Moulder. 1984. Order I. Rickettsiales Gieszczkiewicz $1939,25^{\mathrm{AL}}$, p. 687-729. In N. R. Krieg and J. G. Holt (ed.), Bergey's manual of systematic bacteriology, vol. 1. The Williams and Wilkins Co., Baltimore, Md.

26. Wilson, K. H., H. G. Hills, and P. Zwadyk. Unpublished data. 